\title{
Increased hydrogen peroxide and thiobarbituric acid-reactive products in expired breath condensate of asthmatic patients
}

\author{
A. Antczak, D. Nowak, B. Shariati, M. Król, G. Piasecka, Z. Kurmanowska
}

Increased hydrogen peroxide and thiobarbituric acid-reactive products in expired breath condensate of asthmatic patients. A. Antczak, D. Nowak, B. Shariati, M. Król, G. Piasecka, Z. Kurmanowska. CERS Journals Ltd 1997.

ABSTRACT: Symptoms of bronchial asthma are a manifestation of airway inflammation. Circulatory leucocytes (predominantly eosinophils, mast cells and neutrophils), release inflammatory mediators, including reactive oxygen species, i.e. superoxide anion which is dismutated to hydrogen peroxide $\left(\mathrm{H}_{2} \mathrm{O}_{2}\right)$. Neutrophils from asthmatics generate greater amounts of these species than those of healthy subjects. Some of the $\mathrm{H}_{2} \mathrm{O}$, and thiobarbituric acid-reactive products (TBARs) can evaporate from alveolar lining fluid, and could be expired from the airways of asthmatics. In this study, therefore, we determined whether asthmatic patients exhale more $\mathrm{H}_{2} \mathrm{O}_{2}$ and TBARs than healthy subjects.

We examined 10 healthy subjects as a control group and 21 asthmatic subjects. In asthmatic subjects, forced expiratory volume in one second (FEV1), was $68 \pm 9 \%$ of predicted value, peak expiratory flow rate (PEFR) was $65 \pm 8 \%$ pred, and bronchial reversibility was $34 \pm 5 \%$ of prebronchodilated $\mathrm{FEV} 1$. The mean $\mathrm{H}_{2} \mathrm{O}_{2}$ level measured spectrofluorimetrically in the expired breath condensate of asthmatic subjects was 26 fold higher than that in healthy controls $(0.26 \pm 0.29$ vs $0.01 \pm 0.03 \mathrm{nM}$; $\mathbf{p}<\mathbf{0 . 0 5})$. The concentration of TBARs in breath condensate was also higher in asthmatic patients compared with nonasthmatics $(0.073 \pm 0.071$ vs $0.004 \pm 0.009 \mathrm{nM}$; p<0.05). There was a significant correlation between $\mathrm{H}_{2} \mathrm{O}_{2}$ level and concentration of TBARs in asthmatic patients $(r=0.74 ; p<0.01)$. There was also a strong inverse correlation between $\mathrm{H}_{2} \mathrm{O}_{2}$ content of all asthmatics and $\mathrm{FEV} 1 \%$ pred $(r=-\mathbf{0 . 6 3}$; $\mathrm{p}<0.005)$ and PEFR\% pred $(r=-\mathbf{0 . 5 2} ; \mathrm{p}<0.05)$.

We conclude that there are elevated levels of hydrogen peroxide and thiobarbituric acid-reactive products in expired breath condensate of asthmatic patients, and that measurement of these substances in the expired breath condensate could be a simple, noninvasive method that could be used as a biochemical marker of airway inflammation.

Eur Respir J 1997; 10: 1235-1241.
Dept of Pneumonology and Allergology, Medical University of Lodz, Lodz, Poland.

Correspondence: A. Antczak

Dept of Pneumonology and Allergology Medical University of Lodz

Kopcinskiego St. 22

90-153 Lodz

Poland

Keywords: Breath condensate

bronchial asthma

expired breath

hydrogen peroxide

lipid peroxidation

Received: July 71996

Accepted after revision February 281997

BS was the recipient of a Polish Government scholarship for foreign students.
Symptoms of bronchial asthma may be a manifestation of airway inflammation, which involves the influx of circulating leucocytes (predominantly eosinophils, mast cells and neutrophils) into the bronchial wall [1]. When activated, these cells release mediators and cytokines that amplify the inflammatory process, including release of reactive oxygen species, superoxide radicals $\left(\mathrm{O}_{2}{ }^{-}\right)$and hydrogen peroxide $\left(\mathrm{H}_{2} \mathrm{O}_{2}\right)[2,3]$. Oxidative damage to the epithelium produces hyperresposiveness of human peripheral airways $[4,5]$. Moreover, an intense airway inflammation can be caused either by $\mathrm{H}_{2} \mathrm{O}_{2}$ alone or by newly generated hydroxyl radical $\left(\mathrm{OH}^{*}\right)$ in the presence of iron salts, both stopped by catalase and desferrioxamine (prevents production of $\mathrm{OH} \cdot$ from $\mathrm{H}_{2} \mathrm{O}_{2}$ by transition metal chelation) [6]. Neutrophils from asthmatic patients can generate greater amounts of $\mathrm{O}_{2} \cdot{ }^{-}$and $\mathrm{H}_{2} \mathrm{O}_{2}$ than cells of matched healthy subjects $[7,8]$, and their ability to produce $\mathrm{O}_{2} \cdot{ }^{-}$correlated with the degree of airway hyperresponsiveness to inhaled methacholine [8].
Other sources of $\mathrm{H}_{2} \mathrm{O}_{2}$ in airways of asthmatic patients are activated eosinophils and eosinophil peroxidase, both leading to the decrease of $\beta$-adrenergic receptor density on the guinea-pig lung membrane [9]. Inflammatory cells also generate nitric oxide, combining with $\mathrm{O}_{2}{ }^{-}$ to form peroxynitrite anion $\left(\mathrm{ONOO}^{-}\right)$, which has been shown to induce membrane lipid peroxidation [10]. $\mathrm{H}_{2} \mathrm{O}_{2}$ and other oxidants, as extremely reactive species, are able to react with membrane lipids, lipid components of bronchial lining fluid and lipid mediators to cause their peroxidation, expressed as the production of thiobarbituric acid-reactive substances (TBARs) which follows oxidant injury in the airways. TBARs can serve as markers of lipid oxidative damage, and may themselves be cytotoxic [11].

Reactive oxygen species do not appear to be generated in increased levels in the circulation of asthmatic patients with acute asthma, but so far it has not been determined whether they are generated locally in the 
airways. There are reports of increased $\mathrm{H}_{2} \mathrm{O}_{2}$ in the expired breath of intubated patients with adult respiratory distress syndrome (ARDS) [12]. In our previous study, we found increased $\mathrm{H}_{2} \mathrm{O}_{2}$ in the expired breath condensate of healthy cigarette smokers [13]. Similarly, DeKhuiJZEN et al. [14] revealed increased exhalation of $\mathrm{H}_{2} \mathrm{O}_{2}$ in patients with chronic obstructive pulmonary disease (COPD) [14]. Expired breath condensation is becoming an easy and noninvasive technique for studying volatile and nonvolatile molecules present in expired air [15].

These data as a whole raise the hypothesis that high concentrations of $\mathrm{H}_{2} \mathrm{O}_{2}$ and TBARs can occur locally in the bronchial lining fluid of asthmatic subjects, and reflect oxidant burden in the airways. Some of the $\mathrm{H}_{2} \mathrm{O}_{2}$ and TBARs can evaporate from bronchial lining fluid and can be exhaled with expiratory air of asthmatics. In this study, therefore, we wanted to determine whether asthmatic subjects exhale more $\mathrm{H}_{2} \mathrm{O}_{2}$ and TBAR products than healthy volunteers, and, if so, whether levels of these compounds in expired breath condensate correlate with intensity of bronchospasm expressed as forced expiratory volume in one second (FEV1) and peak expiratory flow rate (PEFR) as percentage of the predicted values.

\section{Materials and methods}

\section{Reagents}

Peroxidase from horseradish type II (HRP; $200 \mathrm{U} \cdot \mathrm{mg}^{-1}$ solid), homovanillic acid (4-hydroxy-3-methoxy-phenylacetic acid), tetramethoxypropane, and thiobarbituric acid (TBA) were from Sigma Chemicals Co. (St. Louis, MO, USA). Glycine, ethylenediamine tetra-acetic acid (EDTA), phosphate-buffered saline (PBS; pH 7.4) and $30 \% \mathrm{H}_{2} \mathrm{O}_{2}$ solution, glacial acetic acid and butanol were purchased from POCH (Gliwice, Poland). Thirty per cent $\mathrm{H}_{2} \mathrm{O}_{2}$ solution was diluted 100 fold with PBS and stored at $4{ }^{\circ} \mathrm{C}$ in the dark. The actual $\mathrm{H}_{2} \mathrm{O}_{2}$ concentration was calculated from its absorbance at $230 \mathrm{~nm}(\mathrm{E}=$ $81 \mathrm{~cm}^{-1} \mathrm{M}^{-1}$ ). Sterile deionized water (conductivity 0.05 $\mathrm{uS} \cdot \mathrm{cm}^{-1}$, Milli Q Plus Water Purification System, New York, USA) was used throughout the study. Aqueous solutions of U.mL ${ }^{-1} \mathrm{HRP}$ with addition of $400 \mu \mathrm{M}$ homovanillic acid were prepared freshly before the assay. All other solutions were stored at $4{ }^{\circ} \mathrm{C}$ for not longer than 14 days.

\section{Study population}

The study subjects included 10 healthy volunteers as a control group (mean \pm SD age $32 \pm 7$ yrs; 6 males and 4 females) and 21 asthmatic subjects (mean \pm SD age $37 \pm 9$ yrs; 12 males and 9 females), who had not suffered from any infectious disease for the last 4 months (table 1), recruited from the Medical University Out-patient Clinic register. Asthmatic subjects were asked to stop any medication with the exception of short-acting $\beta$-agonists (salbutamol or fenoterol), and to attend the clinic, after a 4 week wash-out period, to perform lung function
Table 1. - Characteristics of study population

\begin{tabular}{lcc}
\hline & $\begin{array}{c}\text { Healthy subjects } \\
(\mathrm{n}=10)\end{array}$ & $\begin{array}{c}\text { Asthmatic patients } \\
(\mathrm{n}=21)\end{array}$ \\
\hline Age yrs & $32 \pm 7$ & $37 \pm 9$ \\
Sex M/F & $6 / 4$ & $12 / 9$ \\
FVC \% pred & $98 \pm 3$ & $94 \pm 8$ \\
FEV1 \% pred & $102 \pm 5$ & $68 \pm 9$ \\
PEFR \% pred & $100 \pm 3$ & $65 \pm 8$ \\
FEV1 reversibility \% & $3 \pm 1$ & $34 \pm 5.4$ \\
Asthma duration yrs & - & $10 \pm 8$ \\
\hline
\end{tabular}

Data are presented as mean \pm SD. M: male; F: female; FVC: forced vital capacity; FEV1: forced expiratory volume in one second; PEFR: peak expiratory flow rate; $\%$ pred: percentage of predicted value.

tests. Bronchial asthma was diagnosed according to a history of wheezing dyspnoea and previous documentation of bronchodilator-induced bronchial reversibility, measured as $>15 \%$ increase of FEV1 and the presence of airway hyperreactivity after histamine challenge test, with provocative concentration of histamine causing a $20 \%$ fall in FEV1 (PC20) of $<8 \mathrm{mg} \cdot \mathrm{mL}^{-1}$ according to the method of CocKRofT [16].

Pulmonary function tests, FEV1 and PEFR 50-80\% of predicted value, and bronchial reversibility at least $15 \%$ were basic inclusion criteria. The other inclusion criteria were the ability to stop therapy (other than with $\beta$-agonist) and appropriate pulmonary function test results (as described above). The duration of bronchial asthma was 1-18 yrs, mean \pm SD $7 \pm 5$ yrs. Eight subjects were atopic, as revealed by the presence of immediate positive response to more than 12 common aeroallergen extracts (Allergopharma, Joachim Ganzer KG Reinbeck/Hamburg, Germany) in Poland. Seven asthmatics had positive skin-prick test to house dust. The criteria for definition of nonatopic status were the absence of immediate response on skin-prick test, and no family history of atopy. Spirometry was performed with Flowscreen (Erich Jaeger GmbH \& Co., Germany) equipped with software compatible with American Thoracic Society (ATS) standards [17]. PEFR was measured using a mini-Wright peak flow meter (Clement Clarke International Ltd., Harlow, UK). The highest of three measurements of morning PEFR was recorded. None of the females were pregnant, as assayed by urine pregnancy test (Clearview HCG, Unipath GmbH, Wesel, Germany), or took oral contraceptives. This study was approved by the local Ethics Committee and informed consent was obtained.

\section{Collection of air condensate}

The air condensate was collected in a tube installed in a polystyrene foam container filled with ice and salt as described previously [13]. Study subjects were asked to breathe through the apparatus for $20 \mathrm{~min}$, and at the end of collection $2-5 \mathrm{~mL}$ aliquots of condensate were transferred to Eppendorf tubes. One sample was used for determination of condensate osmolality using an osmometer $800 \mathrm{cI}$ (Trident, Warsaw, Poland). The rest was stored at $-80^{\circ} \mathrm{C}$ for not longer than 7 days until measurement of $\mathrm{H}_{2} \mathrm{O}_{2}$ and TBARs. Our previous experiments 
have shown that, under these conditions, samples of expired breath condensate and $10^{-7} \mathrm{H}_{2} \mathrm{O}_{2}$ solution remain

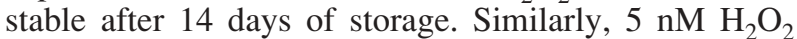
incubated in the device for $20 \mathrm{~min}$ at $0^{\circ} \mathrm{C}$ revealed no significant changes in the ability to react with homovanillic acid [13]. Separate experiments were performed on tetramethoxypropane-model TBAR. Experiments with four different condensate samples and $1 \mathrm{nM}$ tetramethoxypropane solution showed that the concentration of TBAR products was stable for 14 days. Similarly, incubation of $1 \mathrm{nM}$ tetramethoxypropane concentration aliquots in the device for $20 \mathrm{~min}$ at $0^{\circ} \mathrm{C}$ revealed no significant changes of ability to react with TBA. The fluorescence at $546 \mathrm{~nm}$, expressed in arbitrary units (au) was $85 \pm 11$ and $83 \pm 9(n=4)$ for samples before and after incubation, respectively. All collections were performed between 09.00 and $11.00 \mathrm{~h}$, and patients were asked to stop any medication $12 \mathrm{~h}$ before the visit.

\section{Measurement of hydrogen peroxide}

The content of $\mathrm{H}_{2} \mathrm{O}_{2}$ in expired breath condensate was determined according to the method of Ruch et al. [18]. Briefly, $10 \mu \mathrm{L}$ of expired breath condensate was mixed with $90 \mu \mathrm{L}$ PBS and $100 \mu \mathrm{L}$ solution of HRP $\left(1 \mathrm{U} \cdot \mathrm{mL}^{-1}\right)$ containing homovanillic acid and incubated for $60 \mathrm{~min}$ at $37^{\circ} \mathrm{C}$. Afterwards, the samples were mixed with 300 $\mu \mathrm{L}$ PBS and $125 \mu \mathrm{L} 0.1 \mathrm{M}$ glycine- $\mathrm{NaOH}$ buffer $(\mathrm{pH}$ 12) with addition of $25 \mathrm{mM}$ EDTA, and transferred into microcuvettes (PE 5200-4339). The homovanillic acid oxidation product, as a measure of the amount of $\mathrm{H}_{2} \mathrm{O}_{2}$, was determined spectrofluorimetrically using a Perkin Elmer Luminescence Spectrometer LS-50 (Norwalk, CT, USA) operating in the read mode. Slit widths were set at $10 \mathrm{~nm}$ both for emission and excitation, the integrate time was $0.1 \mathrm{~s}$, excitation was at $312 \mathrm{~nm}$ and emission was measured at $420 \mathrm{~nm}$. Readings were converted into $\mathrm{nM}$ using the regression equation $\mathrm{Y}=0.0375 \mathrm{X}-0.3221$ (where $\mathrm{Y}=\mathrm{nmol}$ of $\mathrm{H}_{2} \mathrm{O}_{2}$ per litre of expired breath condensate, and $\mathrm{X}=$ intensity of emission at $420 \mathrm{~nm}$ expressed in au) obtained from three series of calibration experiments with 19 increasing $(0.01-10 \mathrm{nM}) \mathrm{H}_{2} \mathrm{O}_{2}$ concentrations. The confidence level was $95 \%$ and $\mathrm{p}$-value was $<0.03$ and $<0.0001$ for constant and regression coefficient, respectively. The linear least square estimation was used for calculation of the regression equation. The lower limit of $\mathrm{H}_{2} \mathrm{O}_{2}$ detection was $0.1 \mathrm{nM}$.

\section{Measurement of TBAR products}

The content of TBAR species in expired breath condensate was determined according to the method of Y $\mathrm{AGI}_{\mathrm{A}}$ [19]. One hundred microlitres of the condensate was mixed with $2 \mathrm{~mL}$ of TBA solution $(0.67 \mathrm{~g}$ dissolved in $100 \mathrm{~mL}$ of deionized water, then diluted 1:1 with glacial acetic acid). The mixture was boiled for $30 \mathrm{~min}$, allowed to cool at room temperature and chromogen was extracted into $2.5 \mathrm{~mL}$ of butanol by vigorous shaking for $30 \mathrm{~s}$. Following centrifugation $\left(1,500 \times \mathrm{g}\right.$ for $10 \mathrm{~min}$ at $\left.25^{\circ} \mathrm{C}\right)$, TBAR products were measured spectrofluorimetrically using a Perkin Elmer Luminescence Spectrometer LS50 (Norwalk, CT, USA) operating in read mode. Excita- tion and emission wavelengths were 515 and $546 \mathrm{~nm}$, respectively. The regression equation was prepared with tetramethoxypropane as a standard for TBAR species. Tetramethoxypropane reacts with TBA to form the TBAmalondialdehyde adduct characteristic for lipid peroxidation. Readings were converted into nmol using the regression equation $\mathrm{Y}=0.012 \mathrm{X}-0.007$ (where $\mathrm{Y}=\mathrm{nM}$ of TBAR products, and $X=$ intensity of emission at $546 \mathrm{~nm}$ expressed in au) obtained from three series of experiments with 20 increasing $(0.001-5 \mathrm{nM})$ concentrations of tetramethoxypropane.

The confidence level was $95 \%$ and p-values were $<0.03$ and $<0.0001$ for constant and regression coefficients, respectively. The linear least square estimation was used for calculation of the regression equation. The lower limit of TBAR products detection was $0.005 \mathrm{nM}$. A control TBA assay with salbutamol was also performed. Assuming that epithelial lining fluid volume ranges $3-6 \mathrm{~mL}$, and two puffs of salbutamol $(200 \mu \mathrm{g})$ provide roughly $40 \mu \mathrm{g}$ (lung deposition using metereddose application is around $20 \%$ ), we used $10 \mu \mathrm{g}$ of salbutamol dissolved in $1 \mathrm{~mL}$ of distilled water. Distilled water was used as control instead of salbutamol. The study procedure was the same as for condensate TBA assay. Salbutamol turned out not to be TBA-reactive. Both control and salbutamol samples gave results below the sensitivity of the method, and concentration of TBARs in these samples was assumed to be $0 \mathrm{nM}$.

\section{Statistical analysis}

Data from subjects are expressed as the mean \pm SD. For readings that gave results below the limit of sensitivity, the concentration of $\mathrm{H}_{2} \mathrm{O}_{2}$ and TBARs in expired breath condensate were assumed to be $0 \mathrm{nM}$. The differences between results in the group of healthy and asthmatic subjects were determined using student's t-test. A pvalue less than 0.05 was considered to be significant. Pearson correlation was used to determine the relationships between the measured variables. All calculations were performed using Microsoft Excel version 5.0 software.

\section{Results}

To check whether TBARs can evaporate during collection of breath air condensate, preliminary experiments were performed. A sponge soaked with $2 \mathrm{~mL}$ of $5 \mathrm{nM}$ tetramethoxypropane, or distilled water as a control, was fixed in the device next to the saliva trap, and a healthy volunteer was asked to breath out through the device connected with the tube for $20 \mathrm{~min}$. The experiment was repeated three times. The TBAR products were then measured in the condensate sample. The concentration of TBARs in the condensate with tetramethoxypropane was $1.05 \pm 0.12 \mathrm{nM}(\mathrm{n}=3)$ versus $0.00 \mathrm{nM}$ in the control, variation coefficient $11 \%$.

Other preliminary experiments with repeated condensate collection from three volunteers (one healthy subject and two asthmatics) revealed that TBAR products in expired breath remain stable during a 4 day observation (table 2) (variation coefficient for asthmatics 18\%). 
Table 2. - Concentration of TBAR products in expired breath condensate collected for 4 consecutive days from three volunteers

\begin{tabular}{|c|c|c|c|}
\hline \multirow{2}{*}{$\begin{array}{l}\text { Day of } \\
\text { collection }\end{array}$} & \multicolumn{3}{|c|}{ Concentration of TBARs $\mathrm{nM}$} \\
\hline & Healthy & Asthmatic No. 1 & Asthmatic No. 2 \\
\hline \multirow[t]{3}{*}{1} & 0 & 0.061 & 0.042 \\
\hline & 0 & 0.057 & 0.045 \\
\hline & 0 & 0.060 & 0.039 \\
\hline 2 & 0 & 0.059 & 0.040 \\
\hline 3 & 0 & 0.065 & 0.044 \\
\hline \multirow[t]{2}{*}{4} & 0 & 0.060 & 0.047 \\
\hline & $0^{*}$ & $0.066^{*}$ & $0.051 *$ \\
\hline
\end{tabular}

Volunteers (one healthy subject and two asthmatics) were asked to breathe out spontaneously through a mouthpiece, with a saliva trap connected to the tube, and to breathe in with the mouthpiece removed from the mouth for $20 \mathrm{~min}$. They wore a noseclip and their mouth was rinsed with distilled water just before, and at 7 and 14 min during, the condensate collection. On Day 1, three separate collections were performed, and on Day 4, two collections. The interval between collections was 30 min. *: TBARs reading obtained when no saliva trap was used. TBARs: thiobarbituric acid-reactive products.

There were no detectable TBARs in breath condensate collected on the four consecutive days from the healthy subject. There were also no significant differences between three consecutive samples collected on the same day every 30 min (variation coefficient 18\%). Rinsing the mouth with distilled water just before and during condensate collection did not change the level of TBARs in the breath air condensate, which was $0.053 \pm 0.01$ and $0.058 \pm 0.01(n=2)$ before and after rinsing the mouth, respectively. Similar experiments were described in our previous paper on $\mathrm{H}_{2} \mathrm{O}_{2}$ levels in the air condensate, and they revealed that $\mathrm{H}_{2} \mathrm{O}_{2}$ concentration in expired breath remained stable during a 4 day observation and that there were no significant differences in separate samples collected on the same day with 30 min intervals [13]. If patients did not rinse their mouths with distilled water before and during incubation, the $\mathrm{H}_{2} \mathrm{O}_{2}$ level rose due to contamination with saliva. Therefore, in all experiments on the content of $\mathrm{H}_{2} \mathrm{O}_{2}$ in expired breath condensate, a noseclip was worn and the mouth was rinsed with distilled water.

Only one healthy volunteer (10\%) revealed a detectable $\mathrm{H}_{2} \mathrm{O}_{2}$ content in the air condensate $(0.11 \mathrm{nM})$. In 9 healthy subjects $(90 \%)$, the $\mathrm{H}_{2} \mathrm{O}_{2}$ level was below the sensitivity of the method $(0.1 \mathrm{nM})$ and these were assumed to be $0 \mathrm{nM}$. Thus, the mean $\mathrm{H}_{2} \mathrm{O}_{2}$ concentration calculated for the whole group was $0.01 \pm 0.03 \mathrm{nM}$. The $\mathrm{H}_{2} \mathrm{O}_{2}$ level in expired breath condensate of asthmatic subjects $(0.26 \pm 0.29 \mathrm{nM} ; \mathrm{n}=21)$ was 26 fold higher than that in the control group $(\mathrm{p}<0.05)$ (fig. 1$)$. In seven asthmatics (30\%; three males and four females) no detectable $\mathrm{H}_{2} \mathrm{O}_{2}$ concentration was observed.

Two healthy subjects (20\%; one male and one female) had detectable TBARs in the condensate, and the mean content of TBARs in this group was $0.004 \pm 0.009$ $n M(n=10)$. The level of TBARs in expired breath condensate in 21 asthmatic subjects was much higher $(0.073$ $\pm 0.071 \mathrm{nM}$ ), and was 3.2 fold higher than that in the healthy group with positive TBAR assay $(0.022 \pm 0.004$; $n=2$ ) (fig. 2). There were no significant differences between male and female asthmatic subjects with respect

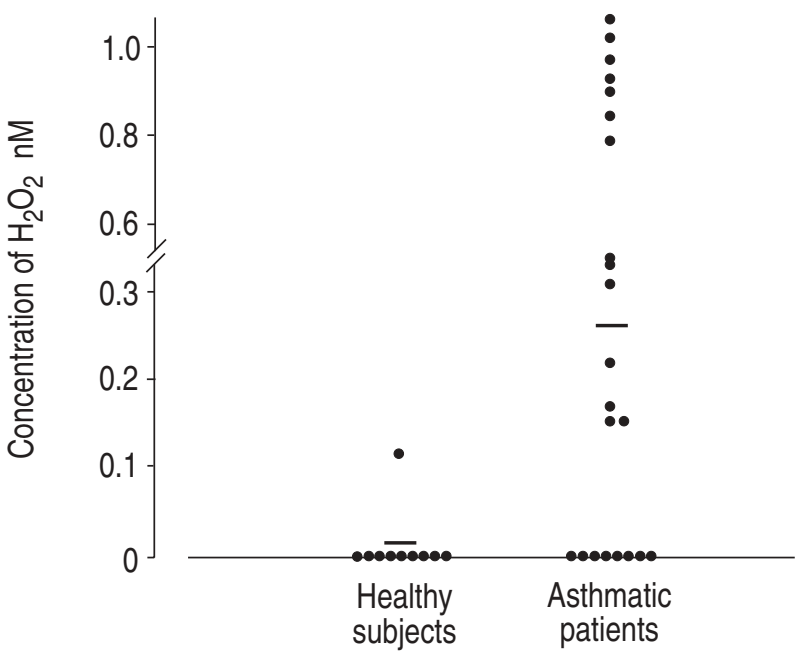

Fig. 1. - Hydrogen peroxide $\left(\mathrm{H}_{2} \mathrm{O}_{2}\right)$ concentration in expired breath condensate of asthmatic patients and healthy subjects. Individual results below the sensitivity of $\mathrm{H}_{2} \mathrm{O}_{2}$ determination by this method $(0.1 \mathrm{nM})$ were assumed to be $0 \mathrm{nM}$. The mean $\mathrm{H}_{2} \mathrm{O}_{2}$ content of breath condensate of all asthmatic subjects was higher than that found in the control group: $0.26 \pm 0.29$ versus $0.01 \pm 0.03 \mathrm{nM}(\mathrm{p}<0.05)$. Horizontal bars indicate means.

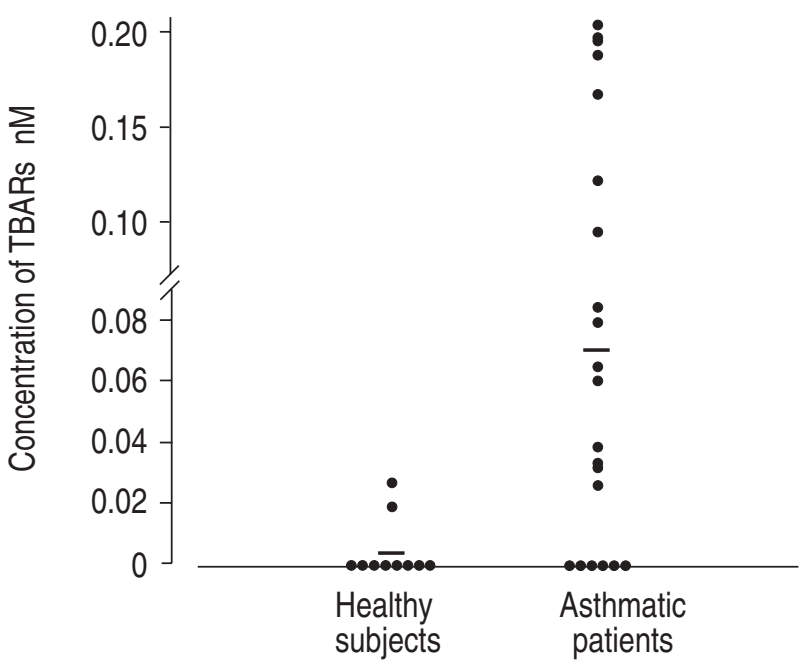

Fig. 2. - Thiobarbituric acid-reactive products (TBARs) in expired breath condensate of asthmatic patients $(n=21)$ and healthy volunteers $(n=10)$. The mean concentration of TBARs in expired breath condensate of asthmatics was much higher than that of healthy subjects: $0.073 \pm 0.071$ versus $0.004 \pm 0.009 \mathrm{nM}(\mathrm{p}<0.001)$. Horizontal bars indicate means.

to levels of $\mathrm{H}_{2} \mathrm{O}_{2}$ and TBARs. A significant positive correlation was found between $\mathrm{H}_{2} \mathrm{O}_{2}$ concentration and TBAR concentration in expired air condensate of asthmatic patients $(\mathrm{r}=0.74 ; \mathrm{p}<0.01)$ (fig. 3 ). There was also an inverse correlation between $\mathrm{H}_{2} \mathrm{O}_{2}$ concentration and FEV1\% pred $(\mathrm{r}=-0.63 ; \mathrm{p}<0.005)$ (fig. 4a) and PEFR\% pred $(\mathrm{r}=-0.52 ; \mathrm{p}<0.05)$ (fig. $4 \mathrm{~b})$, but not reversibility after $\beta$-agonist $(\mathrm{r}=0.01 ; \mathrm{p}<0.8)$ or duration of asthma $(\mathrm{r}=$ $0.08 ; \mathrm{p}<0.7)$ (data not shown).

The mean osmolality of expired breath condensate both of healthy and asthmatic groups was similar, and was $4.63 \pm 0.57(\mathrm{n}=10)$ and $4.8 \pm 0.75 \mathrm{mOsm} \cdot \mathrm{kg}^{-1} \mathrm{H}_{2} \mathrm{O}$ $(n=21)$, respectively. There were also no differences between males and females. The mean osmolality of 


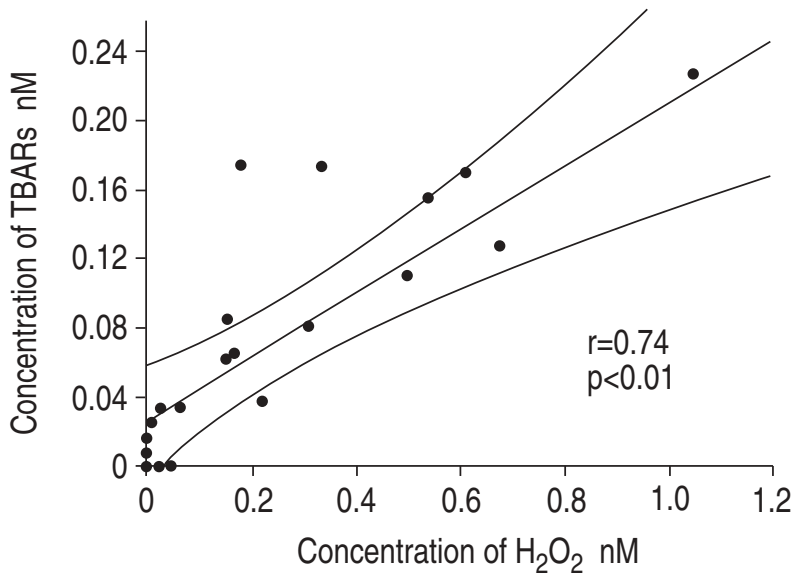

Fig. 3. - Significant correlation between the concentration of hydrogen peroxide $\left(\mathrm{H}_{2} \mathrm{O}_{2}\right)$ and thiobarbituric acid-reactive products (TBARs) in expired air condensate of asthmatic patients $(r=0.74 ; \mathrm{p}<0.01)$. The regression line and $95 \%$ confidence limits are indicated.

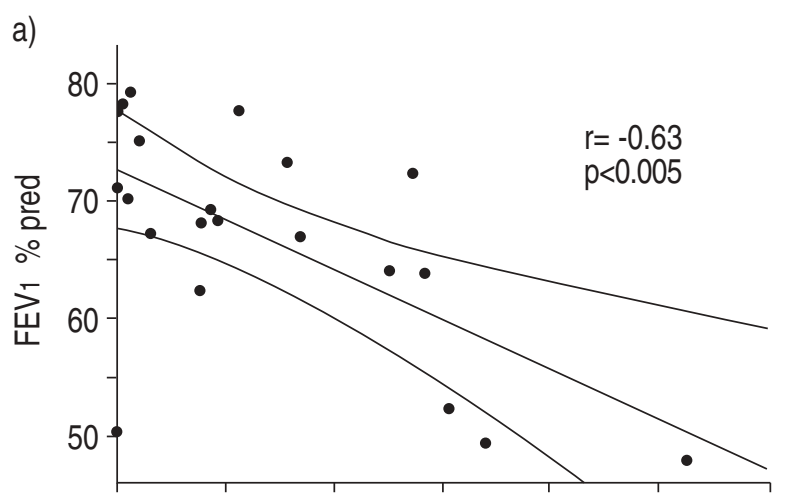

b)

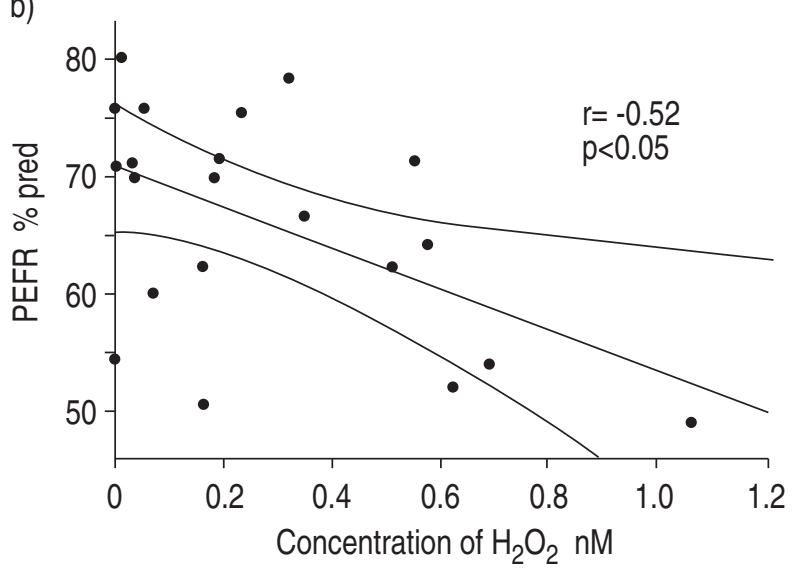

Fig. 4. - a) Significant inverse correlation between the concentration of hydrogen peroxide $\left(\mathrm{H}_{2} \mathrm{O}_{2}\right)$ and the forced expiratory volume in one second $\left(\mathrm{FEV}_{1}\right)$ as $\%$ of predicted value (\% pred) in asthmatic patients $(\mathrm{r}=-0.63 ; \mathrm{p}<0.005)$. b) Significant inverse correlation between the concentration of $\mathrm{H}_{2} \mathrm{O}_{2}$ and the peak expiratory flow rate (PEFR) as \% of predicted value in asthmatic patients $(\mathrm{r}=-0.52 ; \mathrm{p}<$ $0.05)$. Regression lines and $95 \%$ confidence limits are indicated.

saliva is $95 \pm 12 \mathrm{mOsm} \cdot \mathrm{kg}^{-1} \mathrm{H}_{2} \mathrm{O}$, and this clearly indicates that there was no contamination with saliva in the samples analysed. As demonstrated in our previous study, dissolved $\mathrm{CO}_{2}$ and $\mathrm{HCO}_{3}^{-}$are mainly responsible for the relatively high osmolality of expired breath condensate [13].

\section{Discussion}

In this study, we found that asthmatic subjects have higher levels of $\mathrm{H}_{2} \mathrm{O}_{2}$ and TBARs in expired breath condensate than healthy volunteers. A high correlation between these parameters was also found. It seems quite likely that the inflammatory processes involving the respiratory tract lead to increased oxidant production, which, in turn, can be detected by elevated $\mathrm{H}_{2} \mathrm{O}_{2}$ in expired breath.

Oxygen species appear to be important inflammatory mediators and can contribute to some types of lung injury, including ARDS, emphysema and bronchial asthma. Airway inflammation is believed to play a central pathogenic role in the development of bronchial asthma. In the lung, toxic oxygen metabolites can be generated by phagocytic cells. The result of their activation can be a respiratory burst with subsequent production of $\mathrm{O}_{2}{ }^{-}$, which is dismutated to $\mathrm{H}_{2} \mathrm{O}_{2}$. As reactive oxygen species are short-lived, most of the evidence for their deleterious in vivo action comes from indirect studies and data indicating that treatment with free radical scavengers can abolish the harm compared with control groups. Moreover, their ability to be detected depends not only on the amount of oxygen species generated but also on the amount of antioxidant compounds that can react with them. If the antioxidant defence is overcome, reactive oxygen species react with surrounding molecules, and thus lead to tissue injury.

$\mathrm{H}_{2} \mathrm{O}_{2}$ is one of the most stable of toxic oxygen metabolites. It is also volatile and, due to lack of charge, membrane permeable. It is easily excreted and produced extracellularly. Catalase and glutathione peroxidase are basic enzymes regulating the intracellular $\mathrm{H}_{2} \mathrm{O}_{2}$ level [20]. Compared with the intracellular oxidant scavenging network, the airways and extracellular space as a whole have a much weaker reactive oxygen species-scavenging capacity. $\mathrm{H}_{2} \mathrm{O}_{2}$ may, in the presence of iron (Fenton reaction leading to hydroxyl radical generation), oxidize lipids to their hydroperoxy products, thus leading to lung damage. HABIB et al. [21] and Morita et al. [22] demonstrated increased levels of lipid peroxidation products, such as ethane and pentane, in the expired breath after oxidant stress. These results are consistent with a previous study by WiLliams et al. [23], who showed the peroxide-dependent spontaneous chemiluminescence of human breath after $100 \%$ oxygen inhalation.

There are various sources of TBARs. $\mathrm{H}_{2} \mathrm{O}_{2}$ and other oxidants produced by activated phagocytes are able to react with membrane lipids and also with lipid and protein components of bronchial lining fluid and cause their peroxidation. Lipid mediators may be another source of TBAR species. Therefore, the correlation between levels of $\mathrm{H}_{2} \mathrm{O}_{2}$ and TBARs appears to reflect the causeand-effect relationship. The activated inflammatory cells found in bronchoalveolar lavage (BAL) of asthmatic patients produce oxygen species transformed to $\mathrm{H}_{2} \mathrm{O}_{2}$, easily reacting with surrounding lipids [11]. Moreover, $\mathrm{H}_{2} \mathrm{O}_{2}$ could also be a source of hydoxyl radical $\left(\mathrm{OH}^{\cdot}\right)$ through an $\mathrm{Fe}^{2+}$-catalysed Fenton reaction. Hydroxyl radical is extremely reactive, thus easily leading to lipid peroxidation while reacting with these species. The increased content of $\mathrm{H}_{2} \mathrm{O}_{2}$ and TBARs in expired breath condensate of asthmatic subjects is likely to be due to 
increased oxidant production and subsequent lipid peroxidation in bronchial lining fluid, overcoming the antioxidant potential of lower airways.

Theoretically, the production of $\mathrm{H}_{2} \mathrm{O}_{2}$ is much higher than the exhalation of $\mathrm{H}_{2} \mathrm{O}_{2}$ observed in our previous study [13]. This phenomenon may be due to the presence of antioxidants in the airways. Catalase is the basic antioxidant in the alveolar lining fluid. It seems, however, to decompose only high concentrations of $\mathrm{H}_{2} \mathrm{O}_{2}$ efficiently. Thus, it is likely that $\mathrm{H}_{2} \mathrm{O}_{2}$ present in low concentrations is not efficiently scavenged, and, thus, it can be detected in expired breath. On the other hand, in five asthmatic patients, no $\mathrm{H}_{2} \mathrm{O}_{2}$ or TBARs were detected in the condensate, possibly due to antioxidant defence in the airways of these patients. Firstly, during chronic inflammation, antioxidant enzyme activity can be kept at an increased level all the time, and both catalase and glutathione peroxidase can interact to bring about sufficient decomposition of $\mathrm{H}_{2} \mathrm{O}_{2}$. Secondly, during inflammation, an increased permeability of the airway wall can be observed, and this may allow plasma antioxidant factors to diffuse into the alveolar lining fluid increasing the defence against reactive oxygen species.

Our results indicate that, during inflammatory processes, free radical production occurs in the airway and is strong enough to overcome antioxidant defences. Increased levels of $\mathrm{H}_{2} \mathrm{O}_{2}$ and TBARs in expired breath condensate of asthmatics can reflect a situation in which oxidant overload overtakes the capacity of antioxidant protection in the lower airways. However, some of the healthy subjects also had measurable $\mathrm{H}_{2} \mathrm{O}_{2}$ in expired breath condensate, in agreement both with studies showing the peroxide-dependent spontaneous chemiluminescence of human breath, and with our previous work, in which $22 \%$ of nonsmoking subjects revealed a detectable content of $\mathrm{H}_{2} \mathrm{O}_{2}$ in expired breath condensate [13, 24]. Moreover, healthy volunteers excreted micromolar amounts of $\mathrm{H}_{2} \mathrm{O}_{2}$ in urine [25].

In the present study, a high inverse correlation was observed between $\mathrm{H}_{2} \mathrm{O}_{2}$ concentration and $\mathrm{FEV} 1 \%$ pred. This is consistent with several studies on animal models, in which reactive oxygen species could lead to bronchial hyperresponsiveness and subsequent bronchoconstriction. Misawa and co-workers [26] proved that intense airway inflammation can be caused either by $\mathrm{H}_{2} \mathrm{O}_{2}$ alone or by newly generated hydroxyl radical $\left(\mathrm{OH}^{\cdot}\right)$, both stopped by catalase and desferrioxamine. Inhalation of hydrogen peroxide $(1.0 \mathrm{M})$ for 5 min caused significant bronchoconstriction in guinea-pigs. Because $\mathrm{H}_{2} \mathrm{O}_{2}$ enhances prostaglandin $\mathrm{G}_{2}$ production by mast cells [27], and reactive oxygen species can enhance thromboxane $\mathrm{A}_{2}$ ( $\mathrm{TxA}_{2}$ ) production (which is a strong bronchoconstrictor) by alveolar macrophages, it is likely that this compound could lead to bronchoconstriction in our patients. It is also possible that the correlation between $\mathrm{H}_{2} \mathrm{O}_{2}$ and $\mathrm{FEV} 1 \%$ pred could be a coincidence. The two parameters change in the course of inflammation: the increased intensity of inflammation can be followed by impaired pulmonary function values and accompanied by an increased level of $\mathrm{H}_{2} \mathrm{O}_{2}$ in expired breath condensate.

The increased levels of $\mathrm{H}_{2} \mathrm{O}_{2}$ in expired breath, which can be due to airway inflammation, do not only occur in bronchial asthma. Our previous reports have shown that healthy cigarette smokers have increased $\mathrm{H}_{2} \mathrm{O}_{2}$ in expired breath [13]. SzNAJDER et al. [12] found increased levels of $\mathrm{H}_{2} \mathrm{O}_{2}$ in the breath condensate of 43 patients with ARDS [12]. However, they found much higher levels of $\mathrm{H}_{2} \mathrm{O}_{2}$ in the condensate than those measured in the present study. They used neither a saliva trap nor a noseclip, and this could have led to falsely elevated concentrations of $\mathrm{H}_{2} \mathrm{O}_{2}$ in expired breath due to contamination with saliva. On the other hand, Dohlman et al. [28] were very careful about potential salivary contamination, and they also revealed relatively high levels of $\mathrm{H}_{2} \mathrm{O}_{2}$ in expired breath condensate in paediatric patients with asthma $(0.81 \pm 0.70 \mu \mathrm{M})$. The high concentration of $\mathrm{H}_{2} \mathrm{O}_{2}$ observed was primarily due to its elevation in sick patients included in their study. However, the peroxide concentration in the control group was still high $(0.25 \pm$ $0.27 \mu \mathrm{M}$ ) compared to the present results. This discrepancy may be due to the fact that paediatric patients neither rinsed their mouths with distilled water nor wore noseclips, and, thus, traces of $\mathrm{H}_{2} \mathrm{O}_{2}$ from saliva could reach the collecting tube in spite of the use of a saliva trap. Moreover, $\mathrm{H}_{2} \mathrm{O}_{2}$ evaporated from nasal spaces and from saliva could be inspired into the airways and then expired into the collection device and undergo condensation.

Our results indicate that asthmatic patients exhale more hydrogen peroxide and thiobarbituric acid-reactive products, and that free radical processes can occur in the course of airway inflammation with potential subsequent lipid peroxidation in the airways. It is also possible that an elevated content of these oxygen species in expired breath may serve as an indirect marker of free radicalmediated processes, and reflect damaging oxidant overload in the airways, related to inflammation. However, further studies are needed to confirm the potential correlations between bronchial hyperreactivity and levels of hydrogen peroxide and thiobarbituric acid-reactive products in expired breath condensate. If such a correlation was found, it would be a valuable way of studying the effects of anti-inflammatory drugs on airway inflammation, which could be an application of this technique to pulmonary disorders.

\section{References}

1. Kay AB. Asthma and inflammation. J Allergy Clin Immunol 1991; 87: 893-910.

2. Barnes PJ. Reactive oxygen species and airway inflammation. Free Rad Biol Med 1990; 9: 235-243.

3. Kallenbach J, Baynes R, Fine B, Dajee D, Bezwoda W. Persistent neutrophil activation in mild asthma. J Allergy Clin Immunol 1992; 90: 272-274.

4. Abraham WM. The interaction among granulocyte lipid mediators and the generation of oxygen radicals in antigen-induced airway hyperresponsiveness. Adv Prostalandin Thromboxane Leukot Res 1994; 22: 131-140.

5. Hulsmann AR, Raatgeep HR, den Hollander JC, et al. Oxidative damage produces hyperreactivity of human peripheral airways. Am J Respir Crit Care Med 1994; 149: 519-525.

6. Burkitt MJ, Kadiiska MB, Hanna PM, Jordan SJ, Mason RP. Electron spin resonance spin-trapping investigation into the effects of paraquat and desferrioxamine on hydroxyl radical generation during acute iron poisoning. Mol Pharmacol 1993; 42(2): 257-263. 
7. Joseph BZ, Routes JM, Borish L. Activities of superoxide dismutase and NADPH oxidase in neutrophils obtained from asthmatic and normal donors. Inflammation 1993; 17: 361-370.

8. Sustiel AM, Joseph BZ, Rocklin RE, Borish L. Asthmatic patients have primed neutrophils which exhibit diminished responsiveness to adenosine. Am Rev Respir Dis 1989; 140: 1556-1561.

9. Motojima S, Fukuda T, Makino S. Effect of eosinophil peroxidase on beta-adrenergic receptor density on guineapig lung membrane. Biochem Biophys Res Commun 1992; 189: 1613-1619.

10. Radi R, Beckman JS, Bush KM, Freeman BA. Peroxynitrite-induced membrane lipid peroxidation: the cytotoxic potential of superoxide and nitric oxide. Arch Biochem Biophys 1991; 288: 481-487.

11. Janero DR. Malondialdehyde and thiobarbituric acid reactivity as diagnostic indices of lipid peroxidation and peroxidative tissue injury. Free Rad Biol Med 1990; 9: 515-540.

12. Sznajder JI, Fraiman A, Hall JB, et al. Increased hydrogen peroxide in the expired breath condensate of patients with acute hypoxemic respiratory failure. Chest 1989; 96: 606-612.

13. Nowak D, Antczak A, Król M, et al. Increased content of hydrogen peroxide in expired breath of cigarette smokers. Eur Respir J 1996; 9: 652-657.

14. Dekhuijzen PNR, Aben KKH, Dekker I, et al. Increased exhalation of hydrogen peroxide in patients with stable and unstable chronic pulmonary disease. Am J Respir Crit Care Med 1996; 154: 813-816.

15. Scheideler L, Manke HG, Schwulera U, Inacker O, Hamerle H. Detection of nonvolatile macromolecules in breath: a possible diagnostic tool? Am Rev Respir Dis 1993; 148: 778-784.

16. Cockroft DW. Bronchial inhalation tests. I. Measurement of nonallergic bronchial responsiveness. Ann Allergy 1985; 55: 527-537.
17. American Thoracic Society. Standardization of spirometry, 1987 update. Am Rev Respir Dis 1987; 136: 12851298.

18. Ruch W, Cooper PH, Baggiolini M. Assay of $\mathrm{H}_{2} \mathrm{O}_{2}$ production by macrophages and neutrophils with homovanillic acid and horseradish peroxidase. J Immunol Methods 1983; 63: 347-357.

19. Yagi K. A simple fluorometric assay for lipid peroxides in blood plasma. Biochem Med 1986; 15: 212-216.

20. Cantin AM, Fells GA, Hubbard RC, Crystal RG. Antioxidant macromolecules in the epithelial lining fluid of the normal human lower respiratory tract. J Clin Invest 1990; 86: 962-971.

21. Habib MP, Eskelson C, Katz MA. Ethane production rate in rats exposed to high oxygen concentration. $\mathrm{Am}$ Rev Respir Dis 1988; 137: 341-344.

22. Morita SH, Snider MT, Inada Y. Increased N-pentane excretion in humans: a consequence of pulmonary oxygen exposure. Anesthesiology 1986; 64: 730-733.

23. Williams MD, Chance B. Spontaneous chemiluminescence of human breath. J Biol Chem 1983; 258: 3628 3631.

24. Ospital JJ, Kasuyama RS, Tierney DF. Poor correlation between oxygen toxicity and activity of glutathione peroxidase. Exp Lung Res 1983; 5: 193-199.

25. Varma SD, Devamanoharan PS. Excretion of hydrogen peroxide in human urine. Free Rad Res Commun 1990; 8: 73-78.

26. Misawa M, Arai H. Airway inflammation induced by xantine/xantine oxidase in guinea-pig. Agents actions 1993; 38: 19-26.

27. Peden DB, Dailey L, De Graff W, et al. Hydrogen peroxide effects on rat mast cell function. Am J Physiol 1994; 267: L85-L93.

28. Dohlman AW, Black HR, Royall JA. Expired breath hydrogen peroxide is a marker of acute airway inflammation in pediatric patients with asthma. Am Rev Respir Dis 1993; 148: 955-960. 